\title{
Pancoast tumour presenting as shoulder pain with Horner's syndrome
}

\author{
Nimlan Shanmugathas, ${ }^{1}$ Kapil Mohan Rajwani, ${ }^{2}$ Shumontha Dev $^{3}$
}

${ }^{1}$ Emergency Department, Guy's \& St Thomas' Hospitals, London, UK

${ }^{2}$ Department of Neurosurgery, Brighton and Sussex University Hospitals, West Sussex, UK ${ }^{3}$ Emergency Department, Guy's and Saint Thomas' NHS Foundation Trust, London, UK

\section{Correspondence to} Dr Shumontha Dev,

shumontha.dev@gstt.nhs.uk

Accepted 13 January 2019

\section{SUMMARY}

A 54-year-old man presented to the emergency department with a 4-week history of right shoulder pain radiating down his arm, with some associated sensory loss. Further questioning and examination in the department revealed a classical Horner's syndrome; miosis, partial ptosis and hemifacial anhidrosis. An initial chest X-ray was deemed to be unremarkable; however, further review by a radiologist noted asymmetrical right apical thickening. A subsequent high-resolution CT scan of the chest revealed a right-sided Pancoast tumour. This case highlights the importance of a thorough history and examination in identifying a rare cause of shoulder and/ or back pain.

\section{BACKGROUND}

Shoulder pain is naturally thought to have an orthopaedic or rheumatological cause. In carrying out a systemic examination, this man was found to have one of the most learnt-about eponymous cluster of symptoms, and ultimately, eponymous tumours.

\section{CASE PRESENTATION}

A 54-year-old man was sent to the emergency department by his general practitioner with a 4-week history of progressively worsening right shoulder pain radiating down his right arm and into his upper back. He also reported that he had recently been to the gym and noticed only the left

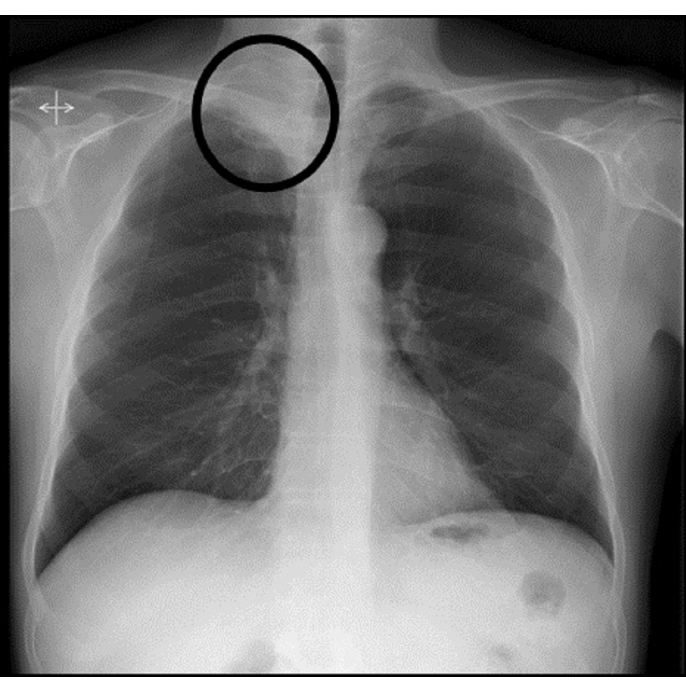

Figure 1 Plain chest radiograph with subtle right apical pleural thickening. Circle seen highlights the abnormality on the chest radiograph of the 'apical thickening'. side of his face was sweating. When asked about other 'abnormal' symptoms, he reported blurred vision in his right eye and felt his right eyelid was 'drooping'. Examination revealed partial ptosis of the right eye, a constricted right pupil and reduced sensation in the right T1 dermatome. Clinically, he had right-sided Horner's syndrome. His only other history, of note, was being an ex-smoker with a 45 -pack-year history.

\section{INVESTIGATIONS}

Baseline biochemical and haematological investigations showed no abnormalities. A chest radiograph was performed that was initially felt to be normal, with no previous radiograph available for comparison (figure 1). A CT scan of the brain was carried out to rule out a central cause for the symptoms, revealing no intracranial abnormality. Following discussion with the on-call neurology team, the patient was discharged with a view to being seen in an urgent neurology outpatient clinic for a 'Horner's work up'.

On discharge, the chest radiograph was reviewed by a radiologist who reported asymmetric right apical pleural thickening (figure 1). A CT scan was organised to further delineate the radiographic changes. This showed a $5.1 \mathrm{~cm}$ right apical Pancoast tumour with infiltration of the posterior right second rib, T1 vertebral body and right T2 neural foramina (figures 2 and 3). A consequent positron emission tomography (PET) scan was in keeping with a right lung primary, with direct invasion into the right second and third ribs shown on the CT scan (figure 4).

\section{OUTCOME AND FOLLOW-UP}

This patient was seen in the urgent 2 -week wait chest clinic and is currently awaiting further investigations for management of the tumour.

\section{DISCUSSION}

When assessing patients in the emergency department, it can often be tempting to go in with tunnel vision, focusing solely on the system in question. In this case, the patient's main symptom was his right shoulder pain, and naturally, an orthopaedic or rheumatological cause was felt to be at fault. However, the history and examination did not fit with such a diagnosis. First, his pain was alleviated with movement and made worse by rest, and second, examination of the right shoulder revealed no deformity, a full range of movement and normal 


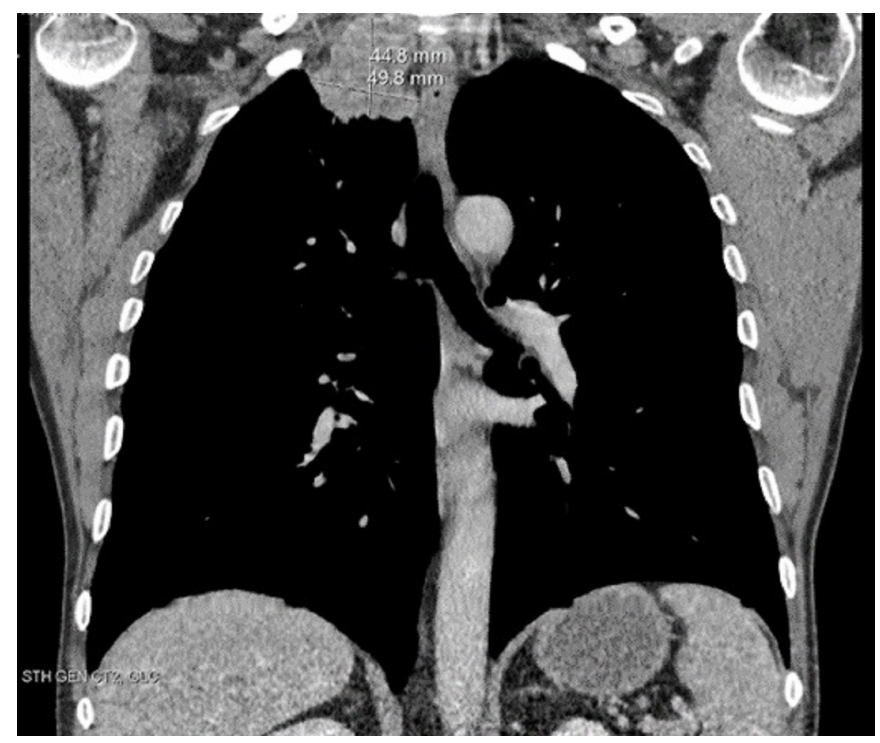

Figure 2 Coronal contrast-enhanced CT scan showing the $5.1 \mathrm{~cm}$ apical mass.

power. The only abnormality from examining the upper limb was a distinct absence of sensation in the T1 dermatome on his right side. In addition, the patient was very forthcoming with textbook features of Horner's syndrome, namely hemifacial anhidrosis and partial ptosis.

Horner's syndrome is the result of an interruption to the cervical sympathetic innervation of the eye. ${ }^{1}$ This constellation of symptoms is accredited to the Swiss ophthalmologist Johann Friedrich Horner following research in 1869, although a study conducted a century earlier recognised a similar pattern following the intentional severance of vagosympathetic nerves in dogs. ${ }^{2}$ Clearly no such act had taken place here, but an underlying cause for such an interruption in sympathetic distribution needed to be deduced.

The causes of Horner's syndrome can be subdivided based on the distribution of anhidrosis; anhidrosis affecting the face, arms and trunk indicates a central cause, anhidrosis affecting the face only indicates a preganglionic cause and the absence of anhidrosis indicates a postganglionic cause. ${ }^{3}$ The patient reported that the asymmetric anhidrosis only affected the right side of his face and denied any such changes to his trunk or limbs. Despite this, a CT brain was still carried out. In retrospect, this could have been omitted from the investigations, but given the subtleties of

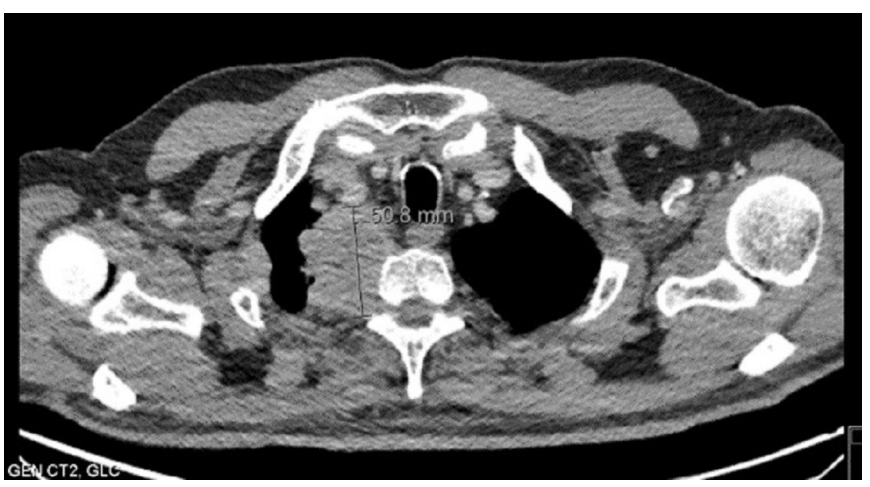

Figure 3 Axial contrast-enhanced CT scan showing the $5.1 \mathrm{~cm}$ apical mass.

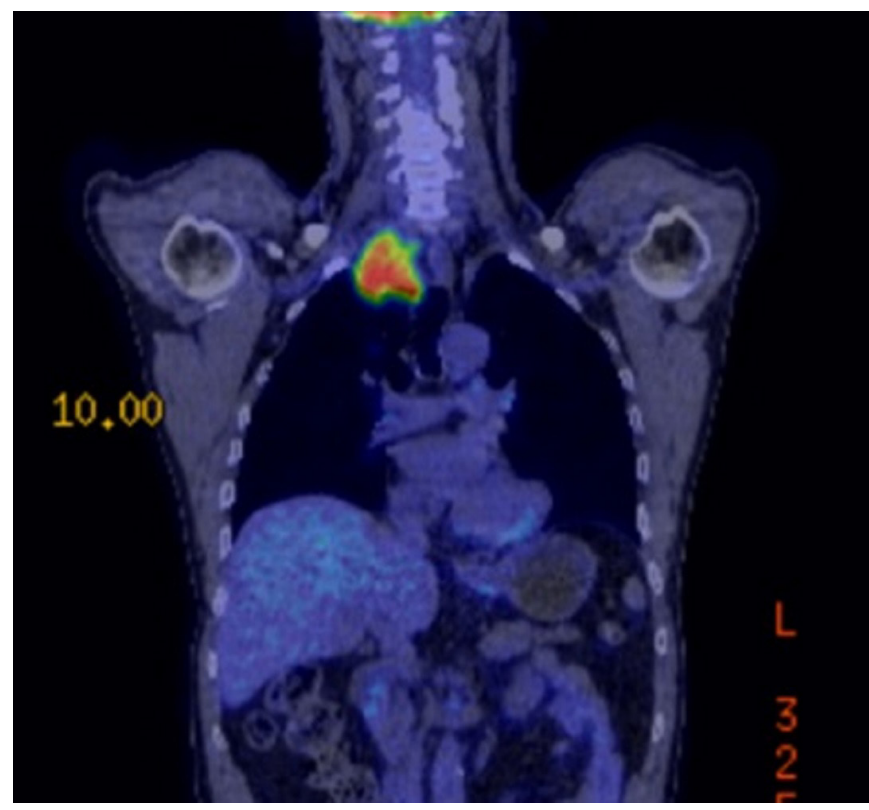

Figure 4 Positron emission tomography scan highlighting increased uptake in the $5.1 \mathrm{~cm}$ apical mass.

such a specific symptom, most clinicians would argue this was an appropriate investigation. ${ }^{4}$

The combination of ipsilateral shoulder pain, paraesthesia along the medial arm and forearm and a preganglionic Horner's syndrome is called Pancoast syndrome. ${ }^{3}$ The most common cause of Pancoast syndrome is an apical lung tumour and so a chest radiograph was requested. ${ }^{5}$ Other differentials include infection, compression of the brachial plexus or spinal roots, pneumothorax and fracture of the first rib or cervical rib. ${ }^{3}$

Pancoast tumours often show subtle changes on plain radiographs, and as such, its presence was initially missed on review in the emergency department, despite a high clinical suspicion. ${ }^{6}$ Fortunately, all chest radiographs in our department are reviewed by a radiologist, leading to it later being reported as showing right apical thickening, prompting a high-resolution CT.

It was only when reviewing the presenting symptom in the context of the patient's history and clinical picture that the diagnosis was finally reached. Had the general practitioner not been suspicious of the patient's concerns over his sweating and the emergency department team not been limited to examining the shoulder alone, this man may have continued to suffer from shoulder pain attributed to a musculoskeletal cause.

\section{Learning points}

- Persistent shoulder and upper back pain should always be investigated, particularly with an atypical history and absence of trauma, as it is often the presenting feature in Pancoast tumours. $^{7}$

- A systemic review will often help to bring together seemingly unrelated symptoms, particularly when combined with a thorough history (including smoking).

- If there is high clinical suspicion for an apical mass, a radiologist may be best suited to review subtle changes in a plain radiograph.

Contributors NS and KMR saw the patient in the emergency department and wrote the article. SD had given advice to write up the case and edited the article 
Funding The authors have not declared a specific grant for this research from any funding agency in the public, commercial or not-for-profit sectors.

Competing interests None declared.

Patient consent for publication Obtained.

Provenance and peer review Not commissioned; externally peer reviewed.

\section{REFERENCES}

1 Kisch B. Horner's syndrome, an American discovery. Bull Hist Med 1951;25:284-28

2 Anon. Johann Friedrich Horner, (1831-1886) "a form of ptosis". JAMA 1969;208:1899-900.
3 Kanagalingam S, Miller NR. Horner syndrome: clinical perspectives. Eye Brain 2015;7:35-46.

4 Smith PG, Dyches TJ, Burde RM. Topographic analysis of Horner's syndrome. Otolaryngol Head Neck Surg 1986;94:451-7.

5 Thompson H, Maxner C, Corbett J. Horner's syndrome due to damage to the preganglionic neuron of the oculosympathetic pathway. Huber A, ed. Symphathetics and the Eye. Stuttgart, Germany: Ferdinand Enke, 1990.

6 Bruzzi JF, Komaki R, Walsh GL, et al. Imaging of non-small cell lung cancer of the superior sulcus. Radiographics 2008;28:561-72.

7 Yacoub M, Hupert C. Shoulder pain as an early symptom of pancoast tumor. J Med Soc N J 1980;77:583-6.

Copyright 2019 BMJ Publishing Group. All rights reserved. For permission to reuse any of this content visit https://www.bmj.com/company/products-services/rights-and-licensing/permissions/

BMJ Case Report Fellows may re-use this article for personal use and teaching without any further permission.

Become a Fellow of BMJ Case Reports today and you can:

- Submit as many cases as you like

- Enjoy fast sympathetic peer review and rapid publication of accepted articles

- Access all the published articles

- Re-use any of the published material for personal use and teaching without further permission

For information on Institutional Fellowships contact consortiasales@bmjgroup.com

Visit casereports.bmj.com for more articles like this and to become a Fellow 